\title{
MIDAS
}

Museus e estudos interdisciplinares

$4 \mid 2014$

Varia e dossier temático: "Museus, utopia e urbanidade"

\section{Ensaio visual}

Visual essay

\section{Nuno Cera}

\section{(2) OpenEdition \\ Journals}

Electronic version

URL: http://journals.openedition.org/midas/756

DOI: $10.4000 /$ midas.756

ISSN: 2182-9543

Publisher.

Alice Semedo, Paulo Simões Rodrigues, Pedro Casaleiro, Raquel Henriques da Silva, Ana Carvalho

\section{Electronic reference}

Nuno Cera, «Ensaio visual », MIDAS [Online], 4 | 2014, Online since 20 February 2015, connection on 02 May 2019. URL : http://journals.openedition.org/midas/756 ; DOI : 10.4000/midas.756

This text was automatically generated on 2 May 2019.

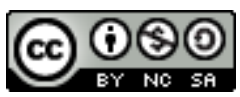

Midas is licensed under a Creative Commons Attribution-NonCommercial-ShareAlike 3.0 International License 


\section{Ensaio visual}

Visual essay

Nuno Cera

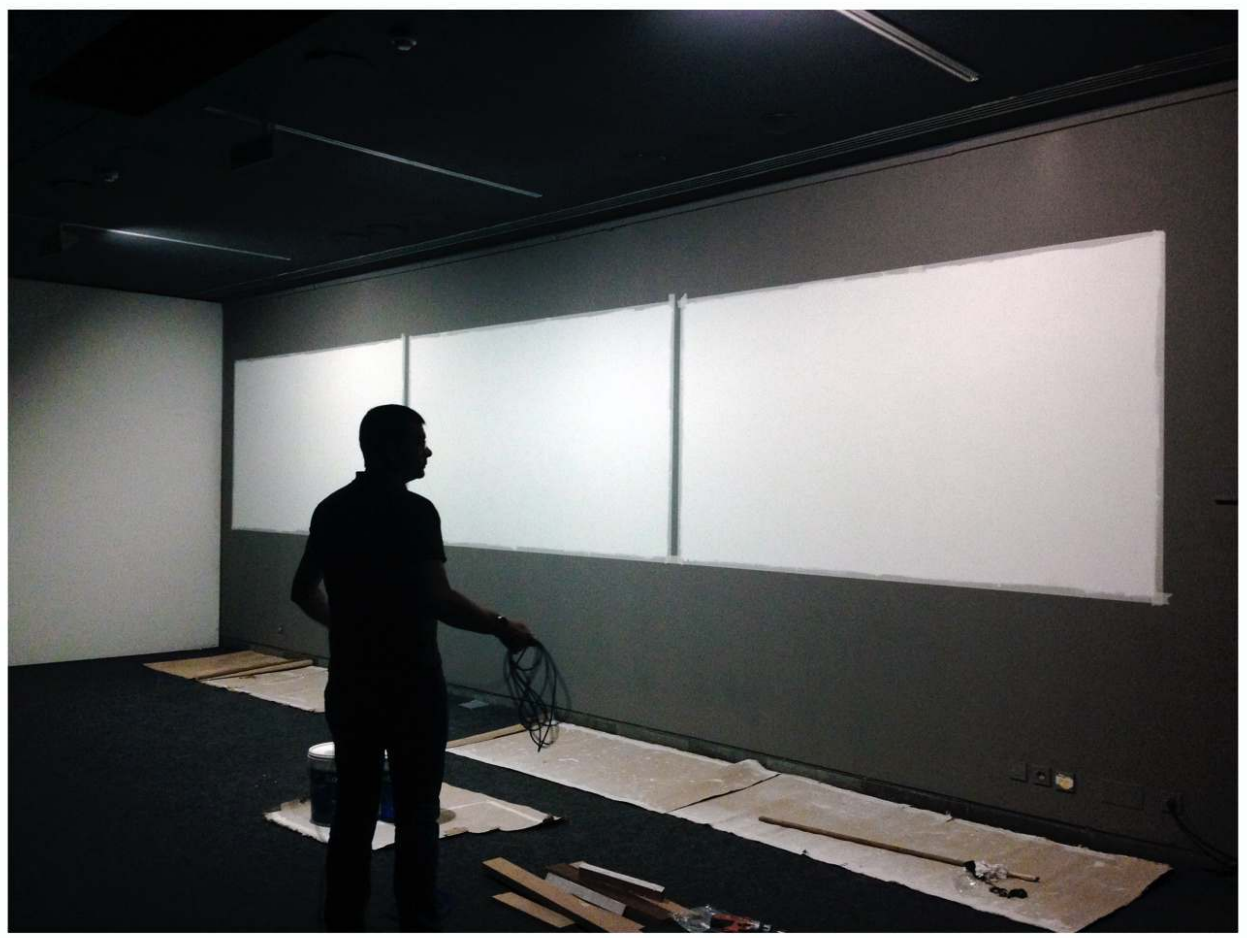

Sem Título (Museu do Chiado), 2014

(c) Nuno Cera. Cortesia do artista 


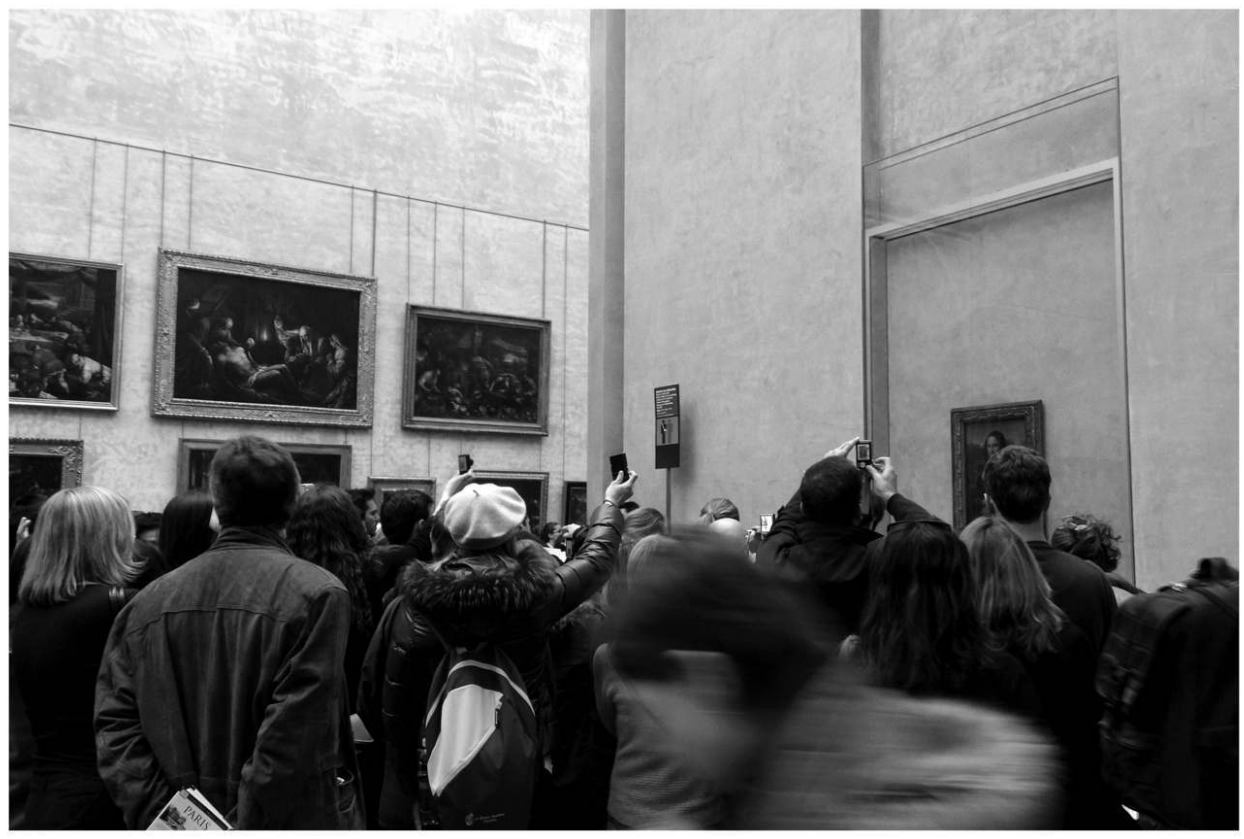

Sem Título (Museu do Louvre), 2013

(c) Nuno Cera. Cortesia do artista

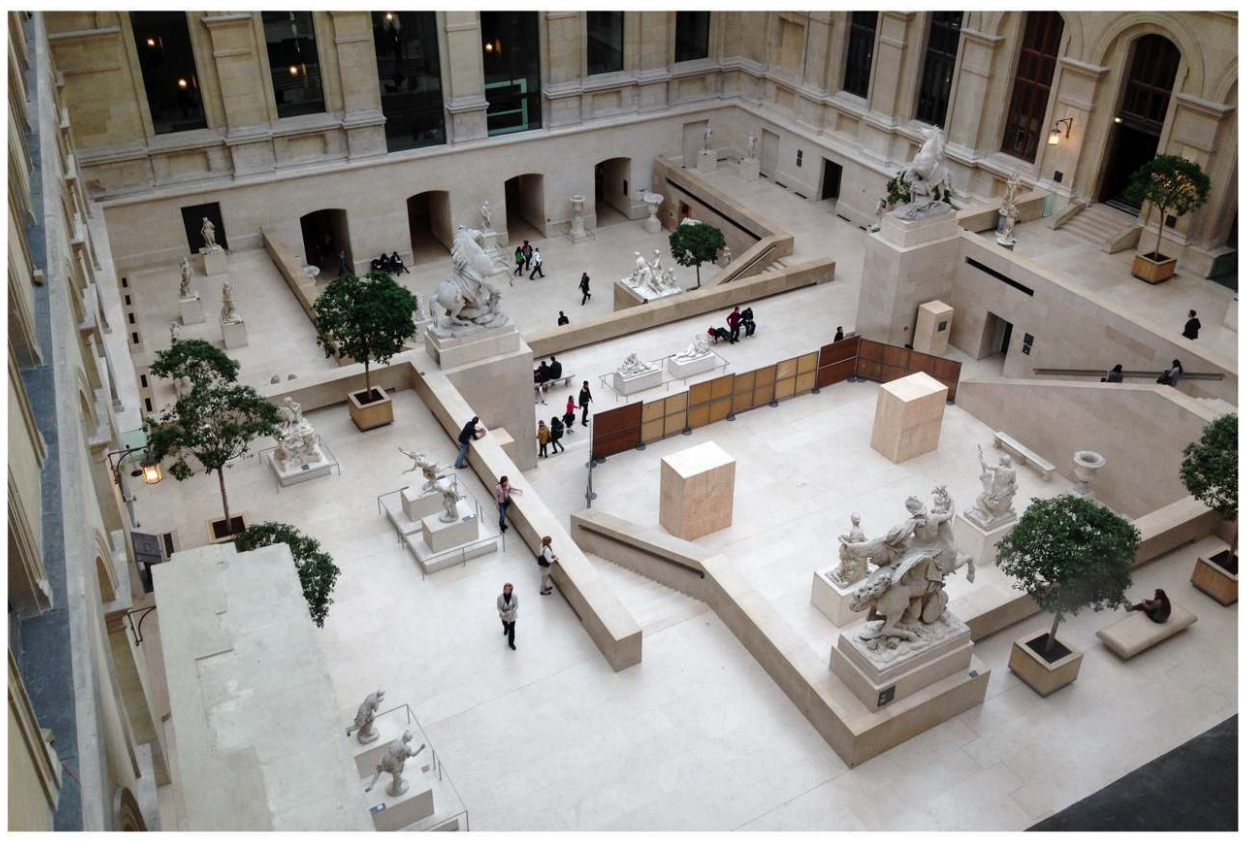

Sem Título (Museu do Louvre), 2013

(c) Nuno Cera. Cortesia do artista 


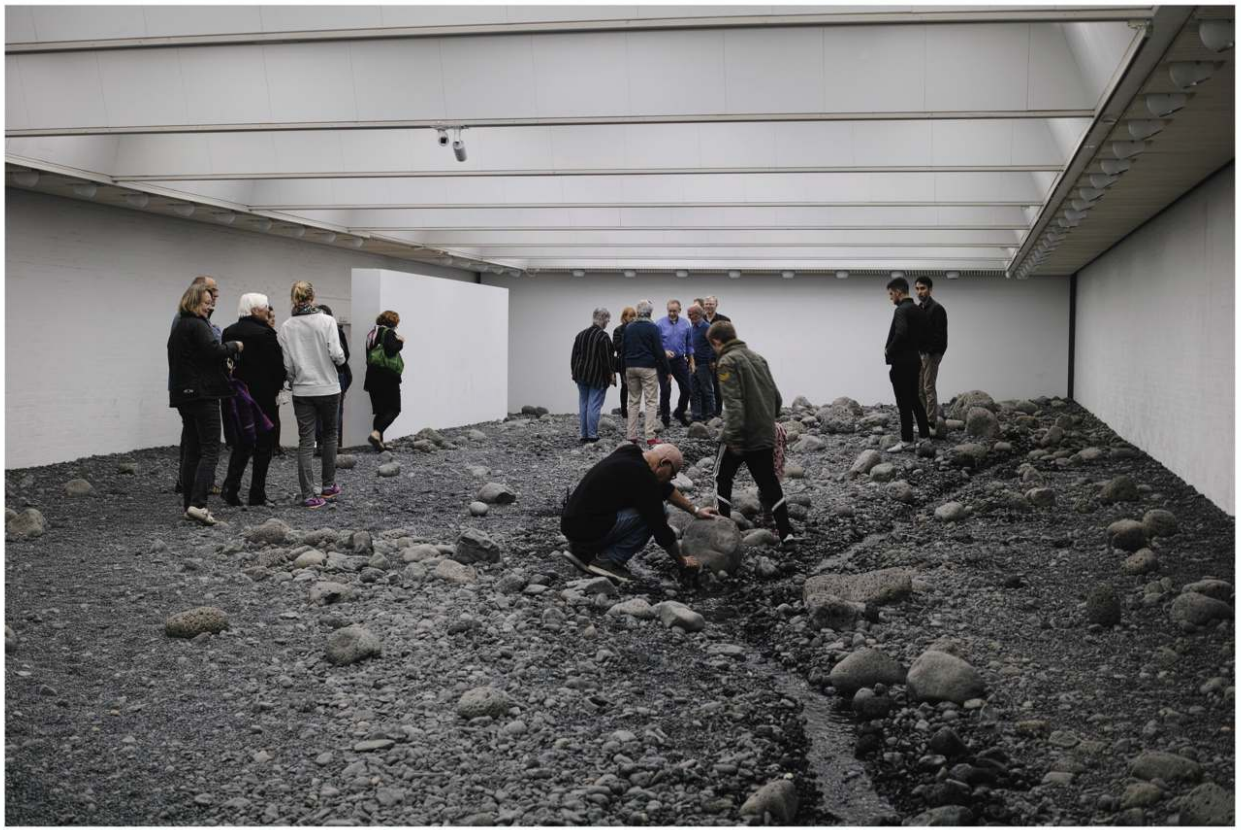

Sem Título (Museu Louisiana), 2014

(C) Nuno Cera. Cortesia do artista

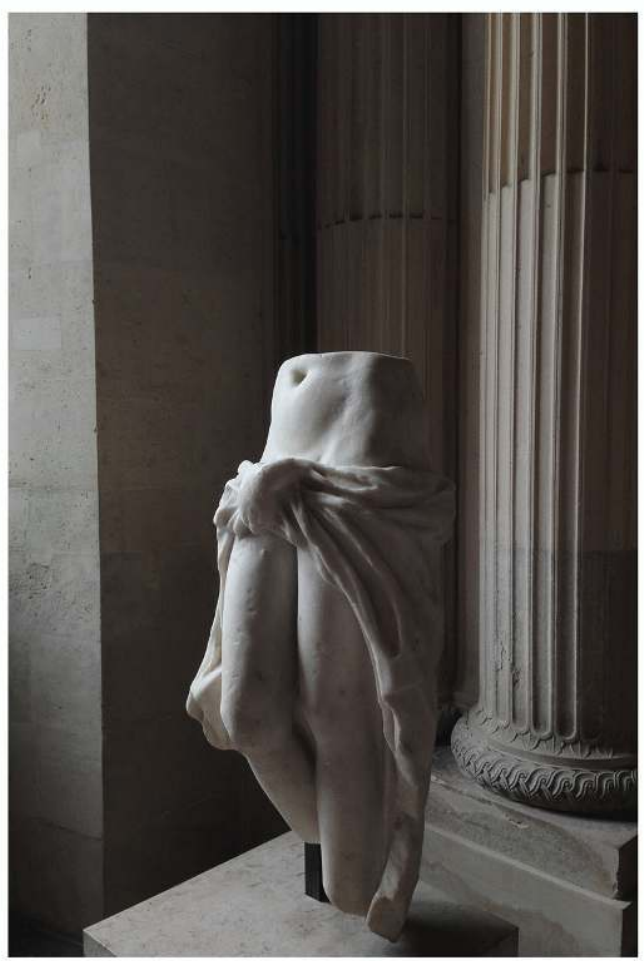

Sem Título (Museu do Louvre), 2013

(c) Nuno Cera. Cortesia do artista 


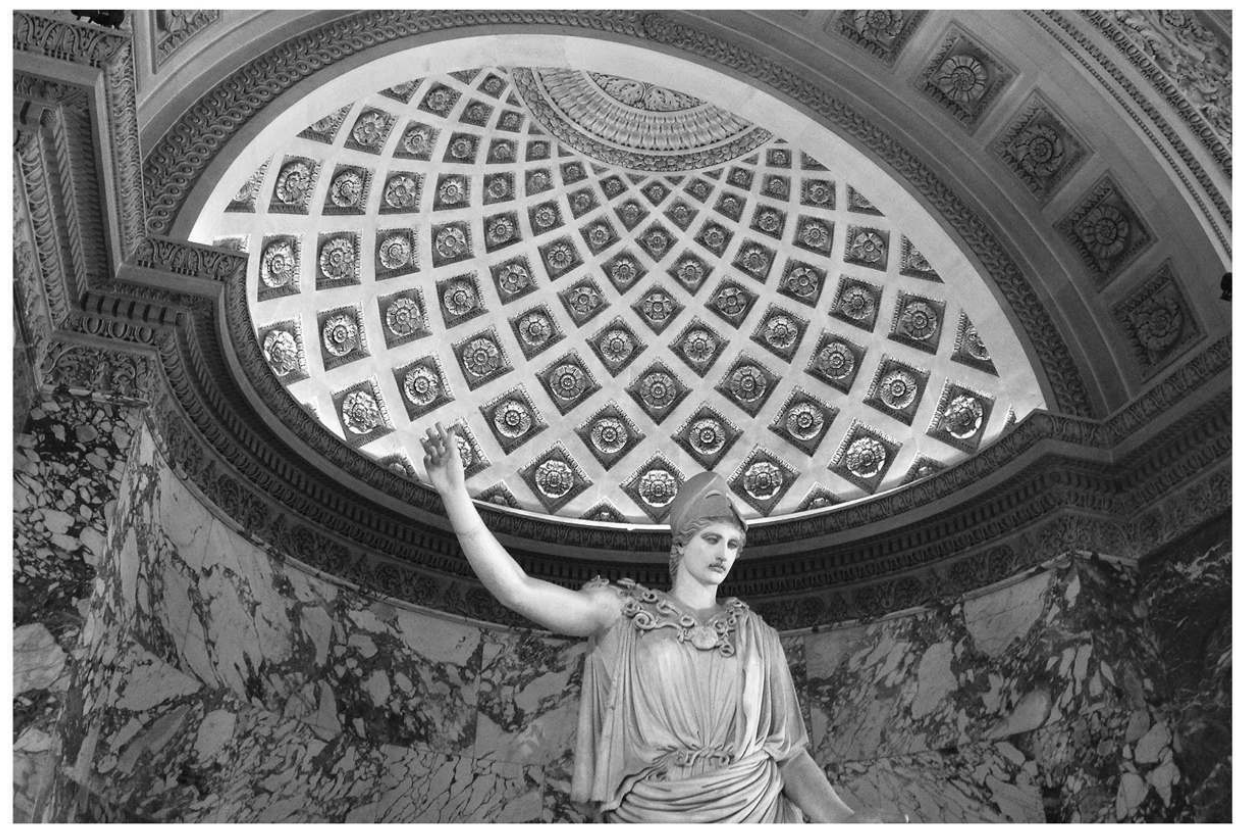

Sem Título (Museu do Louvre), 2013

(c) Nuno Cera. Cortesia do artista

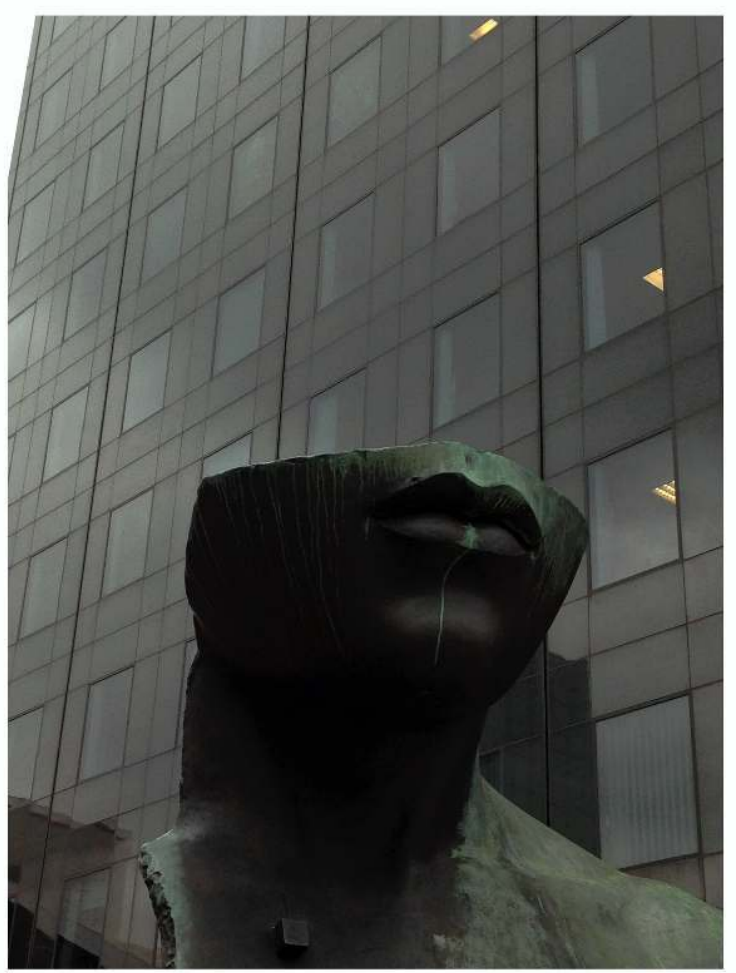

Sem Título (La Défense), 2013

(c) Nuno Cera. Cortesia do artista 


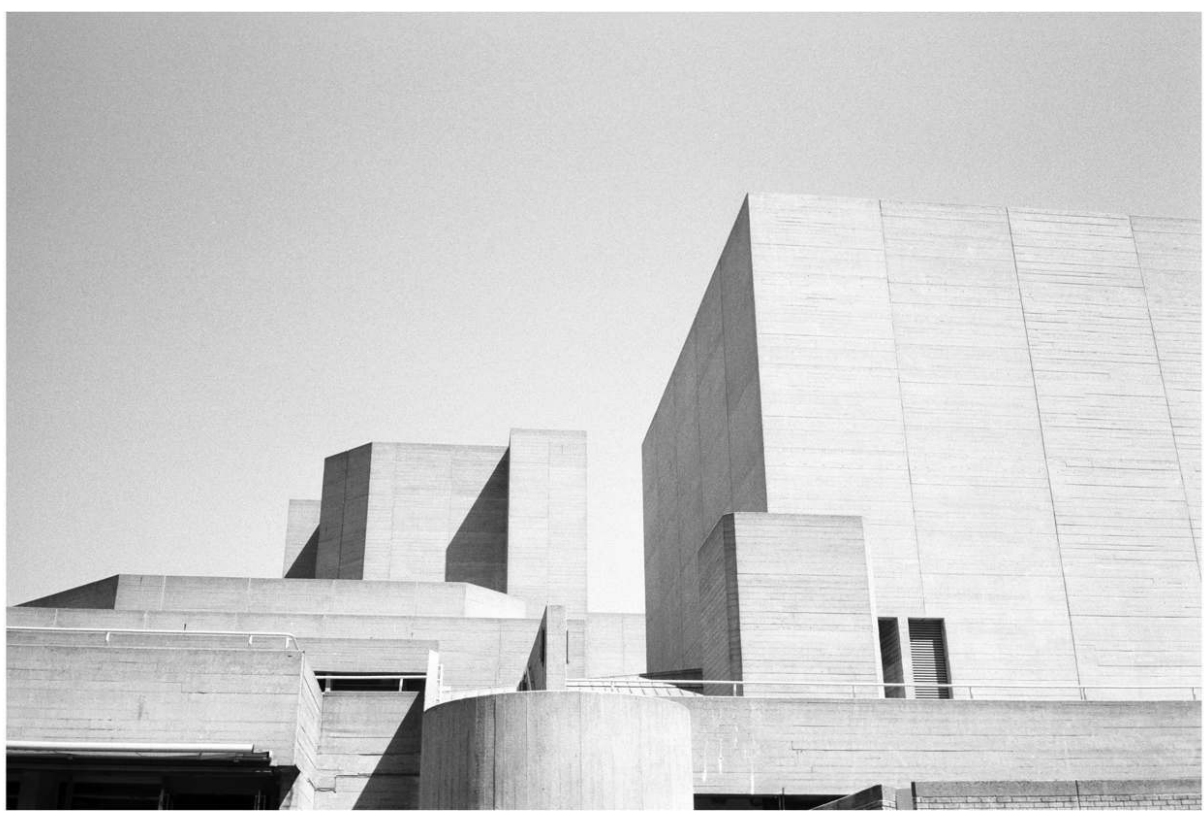

News from Nowhere \#2, 2007

(c) Nuno Cera. Cortesia do artista

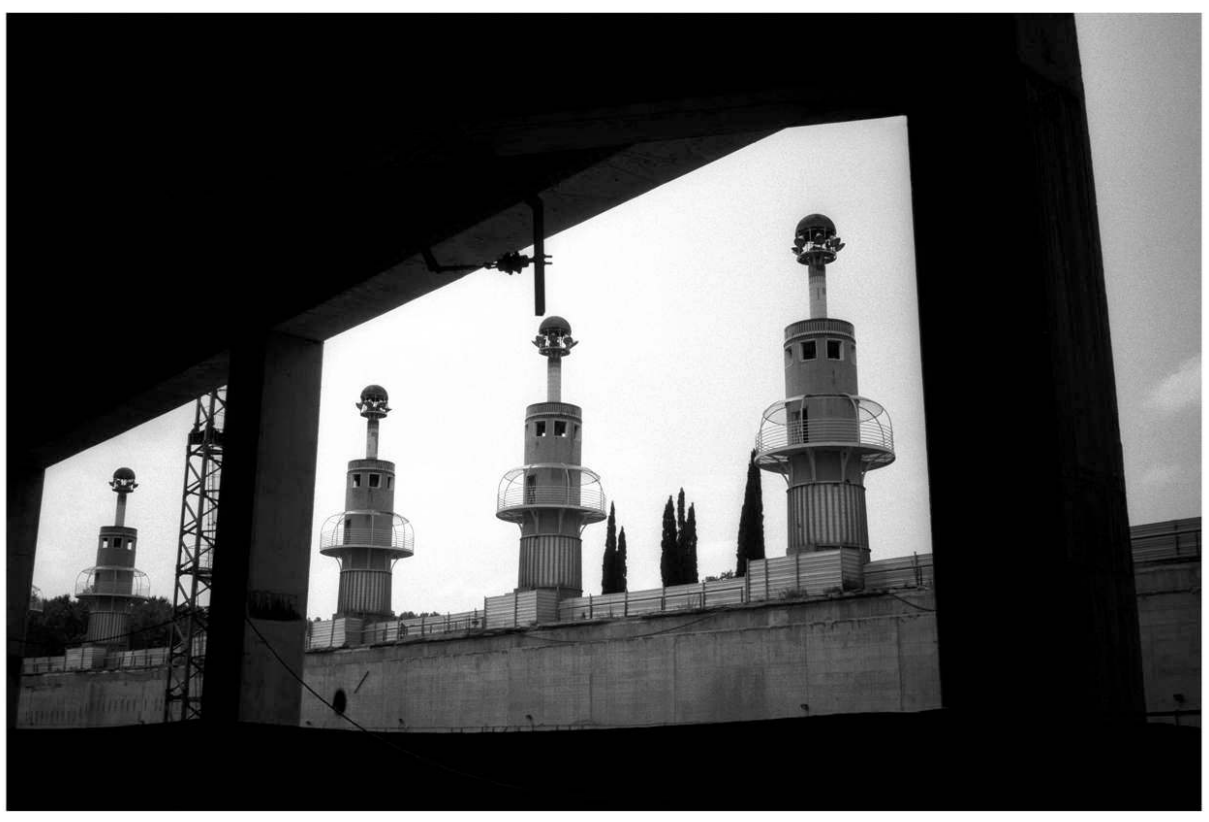

News from Nowhere \#4, 2007

(c) Nuno Cera. Cortesia do artista 


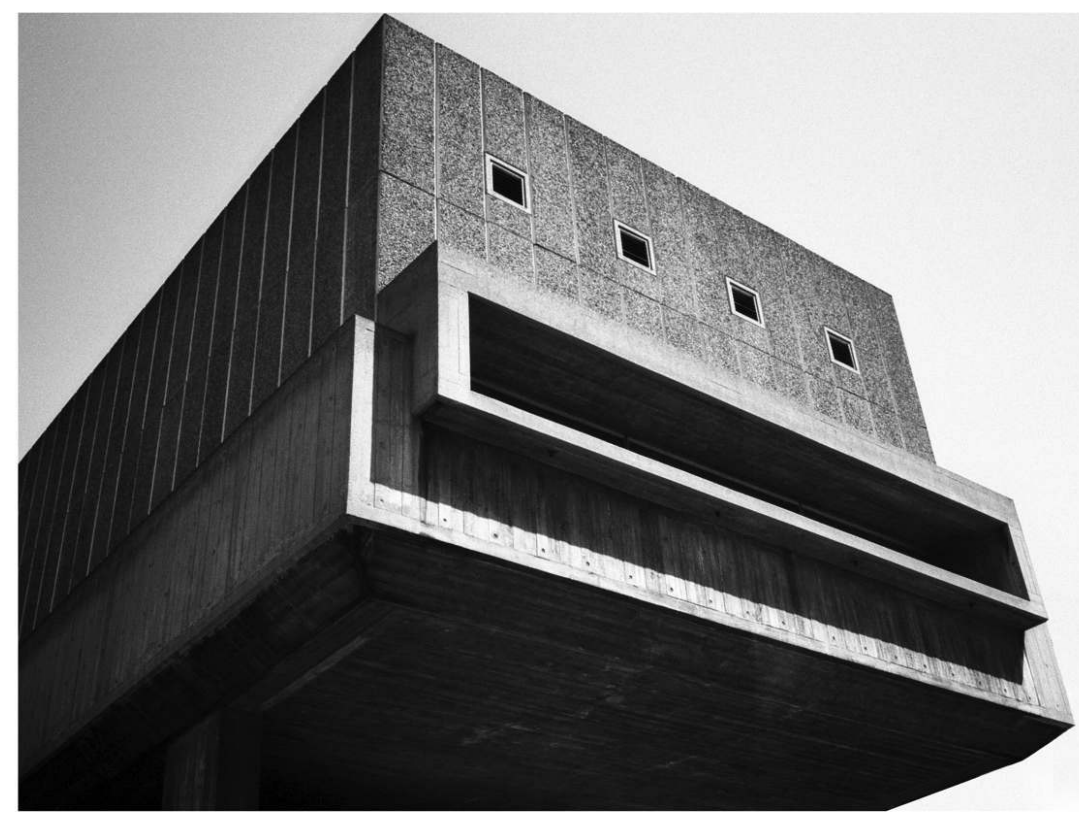

News from Nowhere \#5, 2007

(c) Nuno Cera. Cortesia do artista

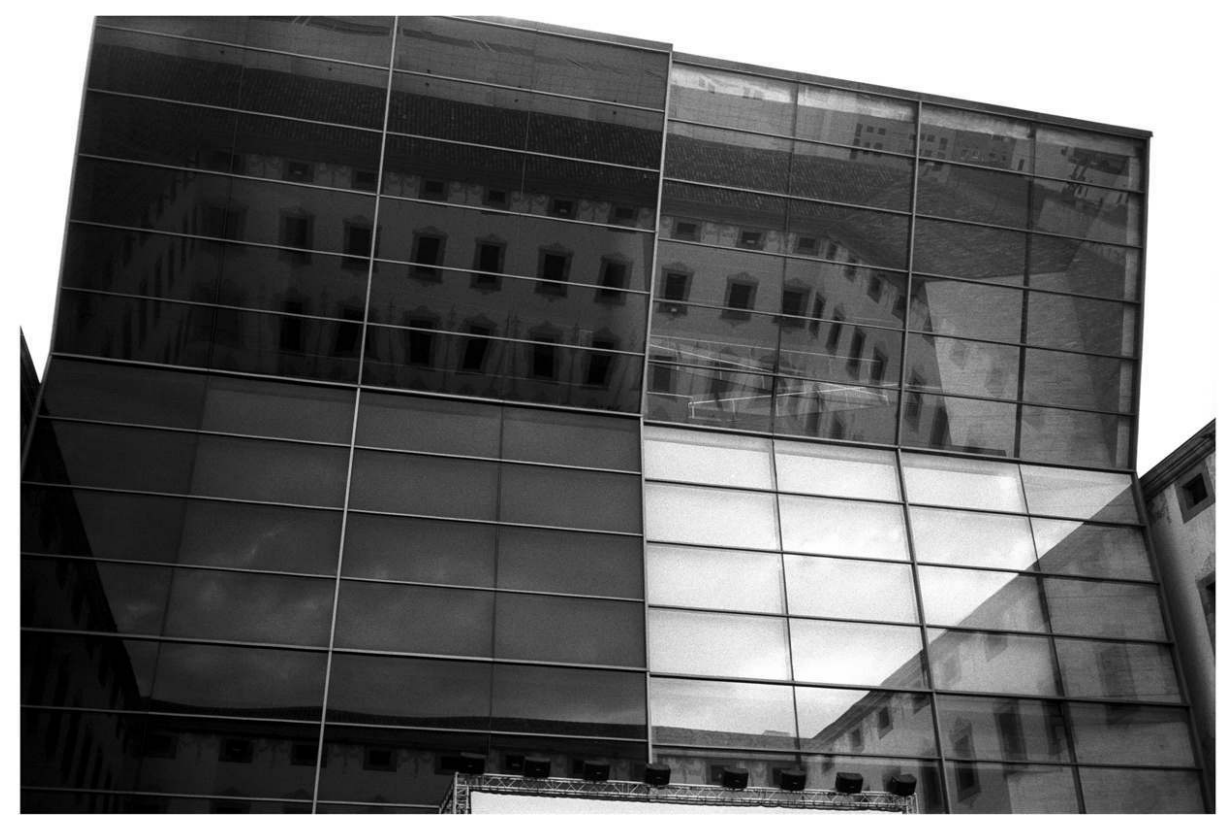

News from Nowhere \#12, 2007

(c) Nuno Cera. Cortesia do artista 


\section{AUTHOR}

\section{NUNO CERA}

Vive e trabalha em Lisboa. É fotografo e cineasta, o seu trabalho aborda questões espaciais, arquitetura e situações urbanas, através de formas ficcionais, poéticas - documentais. Recentes exposições: Sinfonia do Desconhecido, Museu Nacional Arte Contemporânea - Museu do Chiado; Daqui Parece uma Montanha no Centro de Arte Moderna - Fundação Calouste Gulbenkian; AnArquitectura, Teatro Thalia. Prepara atualmente a exposição individual Alpha Béton para o Círculo de Artes Plásticas de Coimbra; uma instalação vídeo para a Pinakothek der Modern, em Munique (Alemanha) e desenvolve os projetos Life is a Building Site, para a Fundação EDP e uma instalação vídeo para a exposição Demo: Polis - 2016, Akademie der Künste, Berlim (Alemanha).

nunocera@gmail.com 